\title{
How infectious is syphilis?
}

\author{
P C SCHOBER, * G GABRIEL, † P WHITE, * W F FELTON, \\ From the Departments of Genitourinary Medicine, ${ }^{*}$ St Thomas's Hospital and + St Bartholomew's \\ Hospital, London; and the $\ddagger$ Department of Genitourinary Medicine, Royal Sussex County Hospital, \\ Brighton
}

SUMMARY In a study of the sexual contacts of patients with primary and secondary syphilis, 65 of $127(51 \%)$ contacts at risk developed syphilis. There was no significant difference between figures for homosexuals $(48 / 98,49 \%)$ and for heterosexuals $(17 / 29,58 \%)$. Our findings are similar to those of the prepenicillin era, but the question, Why are so few contacts infected? remains unanswered.

\section{Introduction}

But how infectious is syphilis? This question is often asked by patients and medical students, but there is little published information on this important aspect of syphilis. Furthermore, early studies concerned heterosexually transmitted syphilis; at present much transmission is between male homosexuals. ${ }^{1}$ We therefore studied the sexual partners of patients with early syphilis and determined how many were infected. Three clinics took part in the study, each with a different clientele. We also determined whether there were any differences in infectivity among patients attending the three clinics since, when combined, the figures provided a better overall answer to the question asked above.

\section{Patients and methods}

The study was carried out in the departments of genitourinary medicine at the Royal Sussex County Hospital, Brighton, and at St Bartholomew's Hospital and St Thomas's Hospital, London. All the participating physicians and health advisers in contact tracing had trained at one centre and followed the same methods.

Patients were entered as index cases if they satisfied two criteria.

(1) Primary or secondary syphilis was diagnosed on the basis of clinical features and darkground identification of Treponema pallidum in serum from a lesion. All diagnoses were supported by positive results to serological

Address for reprints: Dr P C Schober, Department of Genitourinary Medicine, University College Hospital, Gower Street, London WC1

Accepted for publication 31 January 1983 tests (Venereal Disease Research Laboratory (VDRL) test, Treponema pallidum haemagglutination assay (TPHA), and fluorescent treponemal antibody-absorbed (FTA-ABS) test).

(2) Secondary syphilis was diagnosed in the absence of identifiable $T$ pallidum, based on a typical clinical picture and strongly positive serological results (VDRL titre 1/16, TPHA and FTA-ABS test results positive). In all cases there was a rapid clinical response to treatment.

For each index case contacts in the previous 12 weeks were sought by interview with health advisers. Because of the special emphasis of the study the average of $50 \%$ of named contacts attending increased to between $75 \%$ and $100 \%$. If necessary patients were reinterviewed and named contacts sought by personal visits. All contacts included in this study were diagnosed as having syphilis by the criteria used for index cases. In addition early latent syphilis was diagnosed on the basis of positive results to all three serological tests in at least two samples of blood in the absence of clinical signs suitable for darkground examination. Syphilis was excluded by the absence of clinical features and by negative serological results over a three month period from the last exposure to the infection. As far as we are aware no sexual contact had taken antibiotics between the time of infection and diagnosis or the end of the period of observation. Not all contacts were seen in the participating clinics, but they were included in the study if seen in clinics where our criteria for a diagnosis or exclusion of syphilis were followed. Any attempts to assess the frequency and forms of sexual contact between index case and contact were considered impractical. 
At the start of the study some cases were included retrospectively, but most were prospectively studied. An index case could yield more than one contact and each index case and contact formed one pair. The $\chi^{2}$ analysis was used to determine statistical significance.

\section{Results}

Table I gives simple demographic details of the population studied and table II the diagnoses and results for sexual contacts. An overall total of 99 index cases yielded 127 contacts, $65(51 \%)$ of whom had syphilis. Seventy six index homosexuals yielded 98 contacts, of whom $48(49 \%)$ had syphilis. Twenty three index heterosexuals yielded 29 contacts, of whom $17(58 \%)$ had syphilis. These differences were not significant at the $5 \%$ level.
There were considerable differences in the figures for heterosexuals between the participating centres, but those for the homosexuals were uniform (table II).

Of the contacts of primary syphilis, 33 of $57(58 \%)$ were infected and of the contacts of secondary syphilis 32 of $70(46 \%)$ were infected (not significant at the $5 \%$ level) (table III).

\section{Discussion}

We recognise the problems inherent in this method, namely that: $(a)$ couples vary in the frequency and forms of sexual contact and hence in the dose of $T$ pallidum transmitted; $(b)$ the presenting patient may have been infected by his/her partner and not vice versa (it was not possible to determine which partner represented the primary case); and (c) variations $\vec{\nabla}$ existed between centres in staff, patients, $ᄋ$

TABLE I Age and country of birth of index cases and sexual contacts seen at three clinics

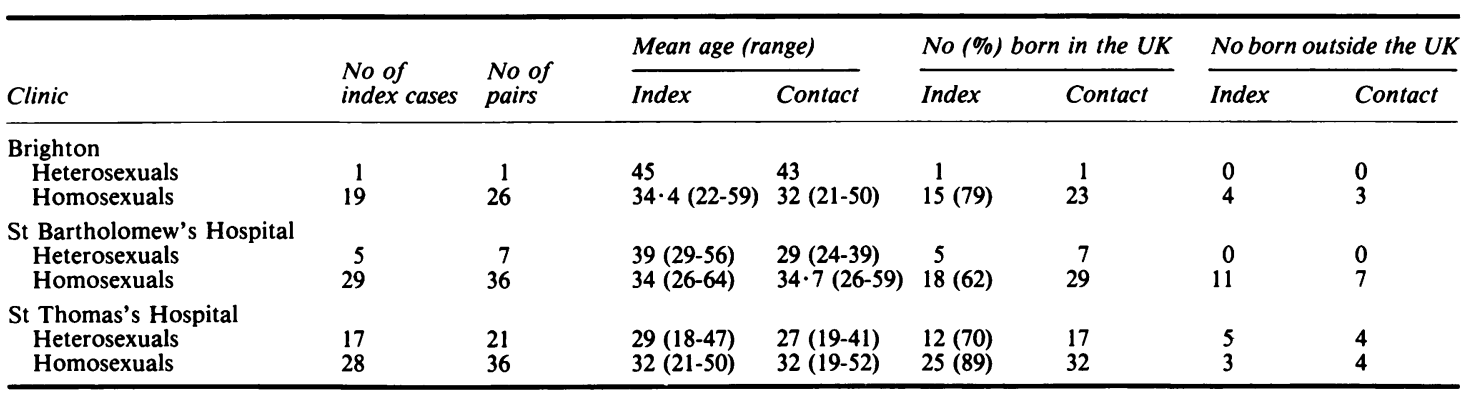

TABLE II Details of diagnosis and infectivity of index cases and sexual contacts seen at three clinics

\begin{tabular}{|c|c|c|c|c|c|c|}
\hline \multirow[b]{2}{*}{ Index case } & \multirow[b]{2}{*}{ Clinic } & \multirow[b]{2}{*}{ No of pairs } & \multicolumn{3}{|c|}{ Diagnosis of sexual contact } & \multirow[b]{2}{*}{$\begin{array}{l}\text { No }(\%) \\
\text { infected }\end{array}$} \\
\hline & & & $\begin{array}{l}\text { Primary } \\
\text { syphilis }\end{array}$ & $\begin{array}{l}\text { Secondary } \\
\text { syphilis }\end{array}$ & $\begin{array}{l}\text { Early latent } \\
\text { syphilis }\end{array}$ & \\
\hline \multicolumn{7}{|c|}{ Primary syphilis } \\
\hline \multirow{8}{*}{ Homosexual } & Brighton & 1 & 0 & 0 & 0 & $0(0)$ \\
\hline & London* & 3 & 0 & 0 & 0 & $0(0)$ \\
\hline & Londont & 10 & 3 & 5 & 0 & $8(80)$ \\
\hline & Total & 14 & 3 & 5 & 0 & $8(57)$ \\
\hline & Brighton & 12 & 2 & 2 & 5 & $9(75)$ \\
\hline & London* & 14 & 0 & 10 & 0 & $10(71)$ \\
\hline & Londont & 17 & 1 & 3 & 2 & $6(35)$ \\
\hline & Total & 43 & 3 & 15 & 7 & $25(58)$ \\
\hline \multicolumn{7}{|c|}{ Secondary syphilis } \\
\hline Heterosexual & Brighton & 0 & 0 & 0 & 0 & 0 \\
\hline & London* & 4 & 1 & 0 & 0 & $1(25)$ \\
\hline & Londont & 11 & 1 & 6 & 1 & $8(73)$ \\
\hline & Total & 15 & 2 & 6 & $i$ & $9(60)$ \\
\hline Homosexual & Brighton & 14 & 0 & 2 & 6 & $8(57)$ \\
\hline & London* & 22 & 2 & 4 & 1 & 7 (32) \\
\hline & Londont & 19 & 3 & 3 & 2 & $8(42)$ \\
\hline & Total & 55 & 5 & 9 & 9 & $23(41 \cdot 8)$ \\
\hline \multicolumn{7}{|c|}{$\begin{array}{l}\text { * St Bartholomew's Hospital } \\
\text { † St Thomas's Hospital }\end{array}$} \\
\hline
\end{tabular}


TABLE III Summary of results

\begin{tabular}{lll}
\hline & No of contacts & No (\%) infected \\
\hline Heterosexual & 29 & $17(58)$ \\
Homosexual & 98 & $48(49)$ \\
Primary syphilis & 57 & $33(58)$ \\
Secondary syphilis & 70 & $32(46)$ \\
\hline
\end{tabular}

motivations, and communication. Ethical and practical considerations prevented a more controlled study.

Previous studies have concerned transmission of syphilis in heterosexual pairs. von Werssowetz, ${ }^{2}$ using a similar protocol to ours, reviewed 3383 contacts in Chattanooga, Tennessee, from 1941 to 1945. He found $48 \cdot 5 \%$ had had or had acquired syphilis during his three month follow up period. Klingbeil and Clark, ${ }^{3}$ using slightly different methods in a study in 1941 at Nashville, Tennessee, found that of 226 married couples both partners were infected in $57 \cdot 1 \%$ of the cases. Alexander and Schoch, ${ }^{4}$ using similar methods to ours in Dallas, Texas, in 1949, reported that 100 of $161(62 \cdot 1 \%)$ subjects exposed to early infectious syphilis were infected.

Thus in four studies performed before and after the introduction of penicillin in the United Kingdom and America $48.5 \%$ to $62 \cdot 1 \%$ of contacts of syphilis became infected. Our figures showed no notable difference between heterosexual and homosexual contacts. Perhaps a more interesting feature is that $37.9 \%$ to $51 \cdot 5 \%$ of contacts did not contract the infection. In our study $42 \%$ of contacts of primary syphilis did not develop the infection, despite the fact that their partners had darkground positive genital or anal lesions. We do not suggest that our results entirely answer the question posed in the title. Despite a notable reduction in incidence, the widespread use of antitreponemal antimicrobials in the community, and great changes in sexual behaviour our figures were remarkably similar to the larger studies in America in the 1940s.

Perhaps the question more perceptive patients, medical students, and doctors should ask is, Why doesn't every contact of infectious syphilis acquire the infection? This shows our lack of knowledge of $T$ pallidum versus host relationships and of the risks associated with different forms of sexual contact and the difficulty in assessing frequency of sexual contact. Further studies are obviously needed.

We thank Mrs Dorothy Palmer and Mrs Maggie Freeman and consultants and health advisers in contact tracing for their help and cooperation.

Part of this paper was presented at the spring meeting of the MSSVD at Jersey, May 1982.

\section{References}

1. British Co-operative Clinical Group. Homosexuality and venereal disease in the UK. Br J Vener Dis 1980;56:6-11.

2. von Werssowetz AJ. The incidence of infection in contacts of early syphilis. J Vener Dis Inform 1948; 29: 132-7.

3. Klingbeil LJ, Clark EG. Studies in the epidemiology of syphilis. J Vener Dis Inform 1941;22: 1-6.

4. Alexander LJ, Schoch AG. Prevention of syphilis. Archives of Dermatology and Syphilology 1949;59:1-10. 